\title{
Identification and mapping of soil erosion areas in the Blue Nile, Eastern Sudan using multispectral ASTER and MODIS satellite data and the SRTM elevation model
}

\author{
M. El Haj El Tahir, A. Kääb, and C.-Y. Xu \\ Department of Geosciences, University of Oslo, P.O. Box 1047 Blindern, 0316 Oslo, Norway \\ Received: 2 December 2009 - Published in Hydrol. Earth Syst. Sci. Discuss.: 12 January 2010 \\ Revised: 8 June 2010 - Accepted: 8 June 2010 - Published: 2 July 2010
}

\begin{abstract}
The area of the Upper Blue Nile in Eastern Sudan is considered prone to soil erosion which is an important indicator of the land degradation process. In this study, an erosion identification and mapping approach is developed based on adaptations to the regional characteristics of the study area and the availability of data. This approach is derived from fusion between remote sensing data and geographical information systems (GIS). The developed model is used to map the spatial distribution of soil erosion caused by the rains of 2006 using automatic classification of multispectral Advanced Spaceborne Thermal Emission and Reflection Radiometer (ASTER) imagery. Shuttle Radar Topography Mission (SRTM) digital elevation model is used to orthoproject ASTER data. A maximum likelihood classifier is trained with four classes, Gully, Flat_land, Mountain and Water and applied to images from March and December 2006. Validation is done with field data from December and January 2006/2007. The results allow the identification of erosion gullies and subsequent estimation of eroded area. Consequently, the results are up-scaled using Moderate Resolution Imaging Spectroradiometer (MODIS) products of the same dates. Because the selected study site is representative of the wider Blue Nile region, it is expected that the approach presented could be applied to larger areas.
\end{abstract}

\section{Introduction}

This paper is the second (the first is Xu et al., 2009) in a set of studies to evaluate the spatial and temporal variability of soil water in terms of natural factors as well as land-use changes as fundamental factors for vegetation regeneration in arid ecosystems in the Blue Nile, Eastern Sudan. This study is concerned with evaluating the spatial distribution of soil erosion as one of the implications of soil degradation in the study region. Such an evaluation is regarded as an important initial inventory in order to further assess the soil water content status (Gomer and Vogt, 2000). Erosion can be a result of anthropogenic disturbance such as overgrazing, soil crust disturbance, and climatic changes such as precipitation increases. Or it can happen as a natural process. The important natural factors controlling erosion are, among others, rainfall regime, vegetation cover, terrain, slope, aspect and river flow network (Linsley et al., 1982). Fluctuating rainfall amounts and intensities have significant impacts on soil erosion rates. Where rainfall intensity increases, erosion and runoff increase at an even greater rate. On the other hand, decreasing annual rainfall triggers system feedbacks related to the decreased biomass production that lead to greater susceptibility of the soil to erode (Nearing et al., 2004). Because of the important role of direct rain drop impact, vegetation provides significant protection against erosion by absorbing the energy of the falling drops and generally reducing the drop sizes, which reach the ground. Vegetation may also provide mechanical protection to the soil against soil erosion via the

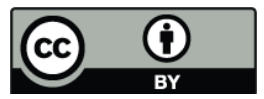

Correspondence to: M. El Haj El Tahir (majdulie@ulrik.uio.no)

Published by Copernicus Publications on behalf of the European Geosciences Union. 


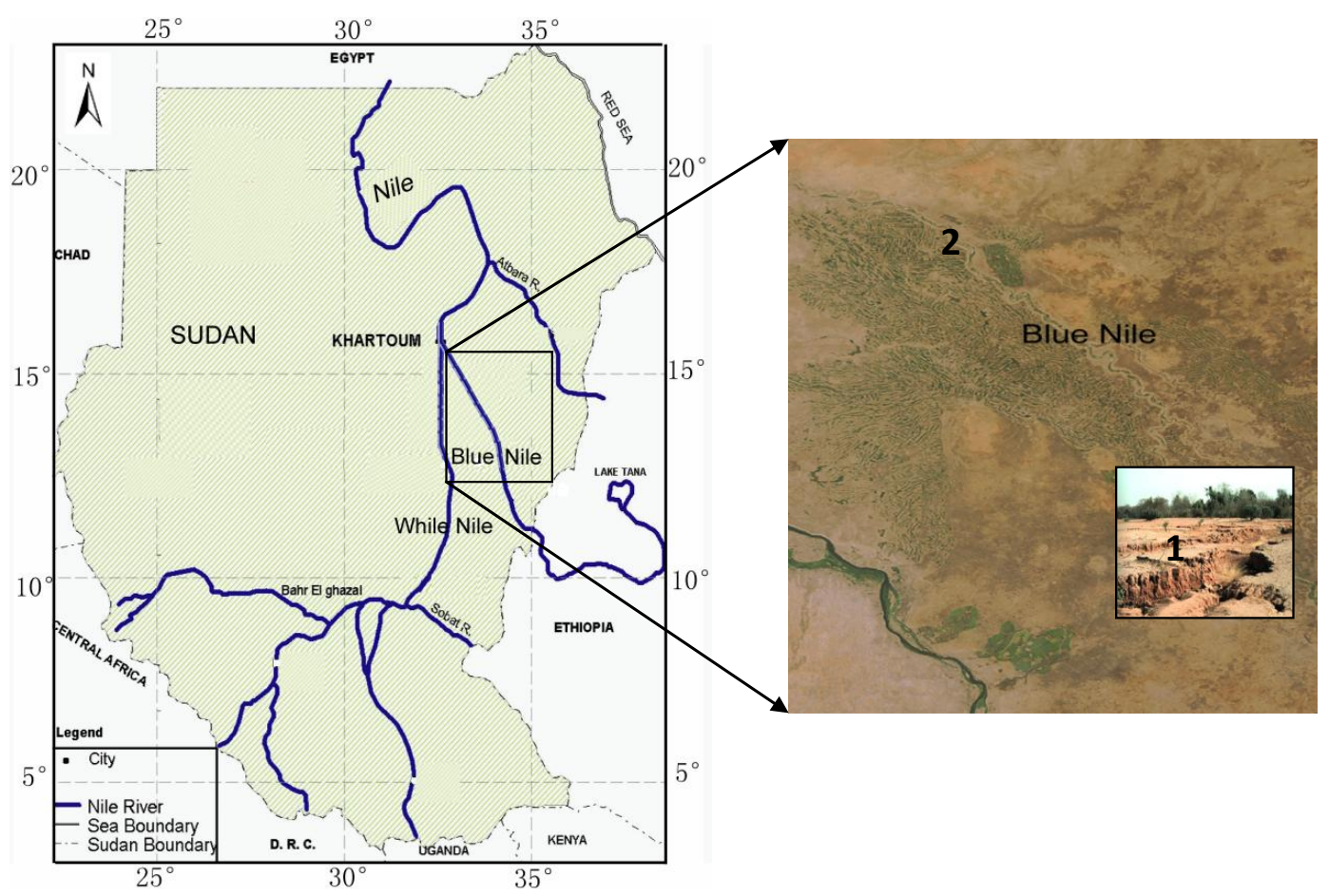

Fig. 1. Map of Sudan and the study region. The area is divided into two scales: 1) ASTER $(60 \times 60) \mathrm{km}^{2}$ for detailed classification and 2) MODIS $(180 \times 180) \mathrm{km}^{2}$ for up scaling and generalizing the results.

root system. In addition, an adequate vegetation cover generally improves infiltration through the addition of organic matter to the soil. Rates of erosion are greater on steep slopes than on flat slopes. The steeper the slope the more effective is splash slope erosion in moving the soil down slope. Overland flow velocities are also greater on steep slopes, and mass movements are more likely to occur in steep terrain. The length of slope is also important. The shorter the slope length, the sooner the eroded material reaches the stream, but this is offset by the fact that overland-flow discharge and velocity increase with length of slope. River flow networks are multiple-branching systems, beginning with tiny rivulets flowing downhill during rainstorms that join into rills and gullies and eventually into creeks and streams. In their headwater regions, river networks are primarily erosional. They acquire soil and weathered rock debris from hill slopes and valley walls. Any abrupt change in any part of the system will propagate uphill across the landscape as well as downstream through these drainage networks (Ritter et al., 2002). The river flow network is a representation of the flow accumulation, also known as contributing area. This is the size of the region over which water from rainfall can be aggregated. As specific catchment area and slope steepness increase, the amount of water contributed by upslope areas and the velocity of water flow increase, hence stream power and potential erosion increase (Moore et al., 1988). The influence of these natural factors on soil erosion is the main concern of this paper.
Arid and semi-arid regions are particularly susceptible to soil erosion due to their low plant cover (Bull, 1981). In time, such soil erosion also results in the loss of soil nutrients, particularly carbon and nitrogen (West, 1991; Mokwunye, 1996), due to the restrictions of feedbacks in carbon and nitrogen cycles between plants, atmosphere and soil (Schlesinger et al., 1990). Considerable literature (Thornes, 1990; Ayoub, 1998; Nakileza et al., 1999; Symeonakis and Drake, 2004) point to the widespread natural resource degradation especially in sub-Saharan Africa, including Sudan. The area of the Upper Blue Nile in Eastern Sudan is considered prone to degradation by Symeonakis and Drake (2004).

The objectives of this study are (1) to improve our understanding of the erosion process in the Upper Blue Nile in Eastern Sudan in terms of natural factors, (2) to identify the erosion areas and estimate their changes using multispectral satellite images from the Advanced Spaceborne Thermal Emission and Reflection Radiometer ASTER sensor together with field data, and (3) to upscale and map the spatial distribution of soil erosion area changes in a larger region using Moderate Resolution Imaging Spectroradiometer MODIS.

To achieve these objectives, an erosion identification and mapping approach is developed based on adaptations to the regional characteristics of the study area and the availability of data. This approach is derived from fusion between remote sensing data and geographical information systems (GIS). 


\section{Study area and data}

\subsection{Description of study area}

The study area lies between latitudes $11^{\circ}$ and $16^{\circ} \mathrm{N}$ and longitudes $33^{\circ}$ and $35^{\circ} \mathrm{E}$ (Fig. 1). It portrays different land use types including agriculture, forests and range areas. Agriculture forms are small holdings, mechanized and river bank farming. The area exhibits high land cover variability. It includes for example the Ar Roseris power dam and its lake. There are a number of forests for example the Okalma forest reserve which is bound by Jabal Okalma (Jabal is the Arabic word for mountain) on the west and Jabal Zign (400 m a.s.l.) on the south east corner. Both mountains constitute a source of sheet floods towards the Okalma forest reserve. The forest reserve is a natural forest composed of a mixture of trees, mainly Acacia seyal and Balanites aegyptiaca plus other species. There is a large variation of age groups from young new regeneration to large groups of forest stands. The forest is related to the surrounding societies providing diversified benefits from the trees and the land. Regeneration and forest development factors are evident. Other areas are abandoned fallow land formed following abandonment of agricultural cropping. To the south-east there is a seasonal Khor Dunya (a gully or a seasonal water course is locally known as khor), running from south west to north east until it joins the Blue Nile. This khor is characterised by the presence of degraded areas, natural regeneration, human activities such as agriculture, pastoralism and small settlements, as well as human intervention to reclaim the vegetation. Gully erosion stripes off the fertile clay soils from the degradational clay plain forming bad-lands known locally as "Kerib" (Mirghani, 2007).

Observed data indicate that the mean annual precipitation in 2006 was $900 \mathrm{~mm}$, of which around $90 \%$ is collected during the rainy season (April-October). For erosion we are interested in the inter-annual and not the annual total of rainfall. The maximum two or three rainy days in 2006 are of interest because it is the maximum rainfall that causes erosion. The maximum rainfall occurred on 8 and 10 May with precipitation levels as high as $109.2 \mathrm{~mm}$ and $200.6 \mathrm{~mm}$, respectively. The mean annual temperature is $28.8^{\circ} \mathrm{C}$. The lowest daily mean temperature is $13^{\circ} \mathrm{C}$ and is measured in December. The highest mean daily temperature is $43.8^{\circ} \mathrm{C}$ and is measured in May. The runoff coefficient is $20-30 \%$ (Ahmed et al., 2006). The year 2006 was an exceptionally wet year. The normal mean annual rainfall is $500 \mathrm{~mm}$ (Abdulkarim, 2006).

\subsection{Economic impacts of gully erosion in the study region}

Although erosion in the centre of the gully is visually apparent (Fig. 2), its effects are not always detectable in terms of changes in soil quality (Ward et al., 2001). This indicates how geomorphologically-apparent desertification (Nir and Klein, 1974; Rozin and Schick, 1996) and changes in

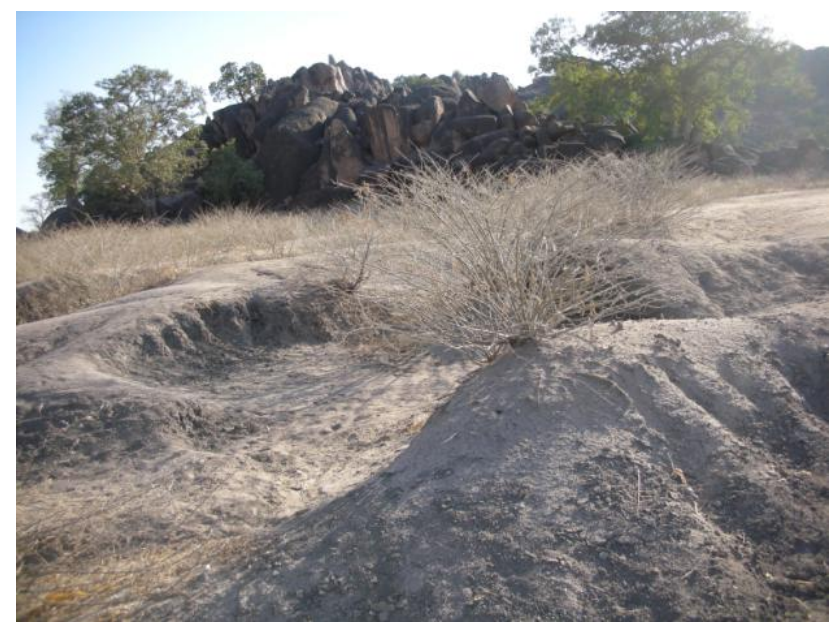

Fig. 2. Erosion in Khor Dunya an example of gully erosion in the Blue Nile region (Photo taken January 2007).

soil nutrient content are not necessarily congruent. Nonetheless, a decline in soil nutrients is recorded as some of the most important soil variables, and thus is likely to significantly impact plant growth. Although the major erosion is usually in the centre of the gully in a strip that is only 5$30 \mathrm{~m}$ wide, most plant biomass and species diversity are as well concentrated there (Ward and Olsvig-Whittaker, 1993). Moreover, the concentration of the water current in the central erosion gully necessarily reduces the water flow to the adjoining sides of the valley during floods. As a consequence of this reduction in water availability, leaching of salts is reduced (Shalhevet and Bernstein, 1968; Dan et al., 1973; Dan and Yaalon, 1982; Dan and Koyumdjisky, 1987) and soil salinity increases on the sides of the valley. Thus, even in the soil that remains un-eroded, soil quality declines over time.

\subsection{Data selection}

Nowadays there is a vast reservoir of remote sensing data, some of them are freely available and easily downloadable from the internet. Remote sensing data are described in terms of spatial resolution, temporal resolution, timing, section of the electromagnetic spectrum, stereo, interferometric or ranging capability, and usability (Kääb et al., 2005). Two types of satellite images are used in this study: Advanced Spaceborne Thermal Emission and Reflection Radiometer (ASTER) and Moderate Resolution Imaging Spectroradiometer (MODIS). In addition, a digital elevation model (DEM) provided by Shuttle Radar Topography Mission (SRTM) was used. Table 1 summarises the data characteristics. The software used are PCI Geomatica version 10.1 and ArcGIS version 9.3. In the following sections each data set is described in detail. 
Table 1. Description of the data.

\begin{tabular}{llllll}
\hline Name & Spatial resolution & Temporal resolution & Swath & Used bands & Date \\
\hline ASTER-Terra & $15 \mathrm{~m}$ & Daily & $60 \times 60 \mathrm{~km}$ & VNIR $(1,2,3)$ & 30 Mar 2006 \\
& & & & SWIR $(5,6,7,8,9)$ & 18 Dec 2006 \\
\hline MODIS-Terra & $500 \mathrm{~m}$ & 15-day average & $180 \times 180 \mathrm{~km}$ & $1,2,5,6,7,8$ & 22 Mar 2006 \\
& & & & & 19 Dec 2006 \\
\hline SRTM & $\begin{array}{l}90 \mathrm{~m} \text { vertical accuracy } \\
(10-20 \mathrm{~m})\end{array}$ & & & & 11 Feb 2000 \\
\hline
\end{tabular}

\subsubsection{ASTER data}

ASTER is a medium-resolution multispectral satellite sensor on the National Aeronautics and Space Administration (NASA) Terra spacecraft, incorporating also an along-track stereo sensor. The latter has stereo angle of about $28^{\circ}$ directed backwards. ASTER has 3 NADIR cameras with bands 1-3 in the visible and near infrared (VNIR), bands 4-9 in the short-wave infrared (SWIR), bands 10-14 in the thermal infrared (TIR). It also has a back-looking stereo camera (band 3B). The spatial width of the seasonal gullies in the study area vary between $2 \mathrm{~m}$ to $20 \mathrm{~m}$. Therefore a combination of ASTER's VNIR and SWIR channels of $15 \mathrm{~m}$ spatial resolution can capture these phenomena. ASTER thermal infrared bands (TIR) bands (B10-B14) whose spatial resolution is $90 \mathrm{~m}$ are therefore not used in this study. Moreover, the reasonable image swath of $60 \mathrm{~km}$ allows gully identification over wide regions. The raw data is retrieved in HDF (hierarchical data format). It contains image data, ancillary data (date, time, orbits, positions, angles, sensor and satellite settings, etc.), and meta-data. Terra is preferred to Aqua because it registers images during the day. ASTER level 1B destripped data is used. The two ASTER images are from 30 March 2006 and 18 December 2006. March on the one hand marks the end of the dry season. The rainy season usually begins in early April. December on the other hand is characterised by high soil moisture conditions since it is just towards the very end of the rainy season. It is also characterised by vigorous seasonal and permanent vegetation growth. The scenes were selected for dates with no cloud cover.

\subsubsection{MODIS data}

At a continental or global scale, coarse spatial resolution data such as from MODIS are preferable because they cover much larger spatial scales simultaneously. MODIS Terra 13Q data version v005, level 2B (available at http://glovis.usgs.gov/), is used. Two MODIS images dating to 22 March 2006 and 19 December 2006 are used. The first image is a 16-days average of daily images between the period 14 to 30 March 2006 and the second is a 16-days average of daily images between the periods 2 to 18 December 2006. MODIS products of ver- sions 4 or higher have been validated and approved for scientific research. Each image has 11 data layers originally. Of these 11 layers, only 6 data layers are used. The layers used are: 1, 2, 5, 6, 7 and 8 which correspond to Normalised Difference Vegetation Index (NDVI), Enhanced Vegetation Index (EVI), red reflectance, Near Infra Red (NIR) reflectance, blue reflectance and Medium Infra Red (MIR) reflectance respectively. The NDVI and EVI are selected because they demonstrate a good dynamic range and sensitivity for monitoring and assessing spatial and temporal variations in vegetation amount and condition. Whereas the NDVI which is chlorophyll sensitive is useful as a vegetation measure in that it is sufficiently stable to permit meaningful comparisons of seasonal and inter-annual changes in vegetation growth and activity. The strength of the NDVI is in its rationing concept, which reduces many forms of multiplicative noise (illumination differences, cloud shadows, atmospheric attenuation, and certain topographic variations) presents in multiple bands. EVI is more responsive to canopy structural variations, including Leaf Area Index (LAI), canopy type, plant physiognomy, and canopy architecture (Gao et al., 2000). The two vegetation indices (VIs) complement each other in global vegetation studies and improve upon the detection of vegetation changes.

ASTER and MODIS are complementary in resolution, offering a unique opportunity for scale-related studies (Vrieling et al., 2008). ASTER with its finer spatial resolution and better accuracy is used to identify erosion areas and to quantify the erosion for the small area, while MODIS is used to up scale ASTER results for sake of understanding erosion on a larger scale for the wider Blue Nile region in Eastern Sudan.

\subsubsection{SRTM data}

Shuttle Radar Topography Mission (SRTM) is a single-pass InSAR, which provides elevation data on a near-global scale (between $60^{\circ} \mathrm{N}$ and $54^{\circ} \mathrm{S}$ ), and it is the most complete highresolution digital topographic database of Earth. It has gaps in it that resulted from shadow, SRTM3 is freely available. Where available, the SRTM indeed represents a revolutionary data set for all kinds of terrain studies (Kääb et al., 2005). 


\section{Methodology}

\subsection{Method overview}

The flow diagram in Fig. 3 demonstrates the method used in developing this erosion area model. Briefly speaking, the study area (Fig. 1) is divided into two scales:

1. A $60 \times 60 \mathrm{~km}$ (approx. $3600 \mathrm{~km}^{2}$ ) scale. This area is studied in detail with the aid of the finer resolution of two ASTER images dated 30 March and 18 December of the year 2006. The aim is to detect the bi-temporal changes in eroded area that have resulted from the seasonal rains of 2006. An initial preprocessing of the raw data is undertaken. ASTER images are then used to generate photogrammetric DEMs. The qualities of these DEMs are then compared to SRTM. The best DEM of the three is hence used to accurately orthorectify ASTER images. The orthoimages are then trained using a supervised classifier into four different land cover classes; Gully, Flat_land, Mountain and Water. The outcome of the classification is validated against field data. Finally, the change in eroded area between the two scenes is estimated. As such the erosion area between the period March and December 2006 is determined at this scale.

2. For up-scaling the verified ASTER results to an $180 \times 180 \mathrm{~km}$ (approx. $32400 \mathrm{~km}^{2}$ ) scale, two MODIS images dating 22 March and 19 December 2006 are used. The MODIS images are pre-processed and georefrenced before undertaking a supervised classification using the same land cover classes and training areas as ASTER. The outcome of MODIS classification is validated against field data and finally the seasonal change in erosion area for the whole Blue Nile region is detected.

\subsection{Pre-processing: ASTER DEM generation and or- thorectification}

Due to radar shadow, foreshortening, layover and insufficient interferometric coherence, the SRTM has significant voids in high mountains. Therefore in this study two DEMs are extracted from each one of the two ASTER images. The qualities of these two DEMs are then compared to SRTM and the most accurate of the three is used further for orthoprojection of ASTER images. Orthoprojection is a mandatory pre-processing step necessary to prevent strong topographically induced distortions between the images in the rugged study area which is characterised by elevation ranging approximately from $10 \mathrm{~m}$ to $1500 \mathrm{~m}$. DEM generation from satellite imagery uses photogrammetric principles. Toutin (2001, 2002), and Toutin and Cheng $(2001,2002)$ outlined the main digital processing steps for DEM generation from ASTER within the PCI Geomatica software.

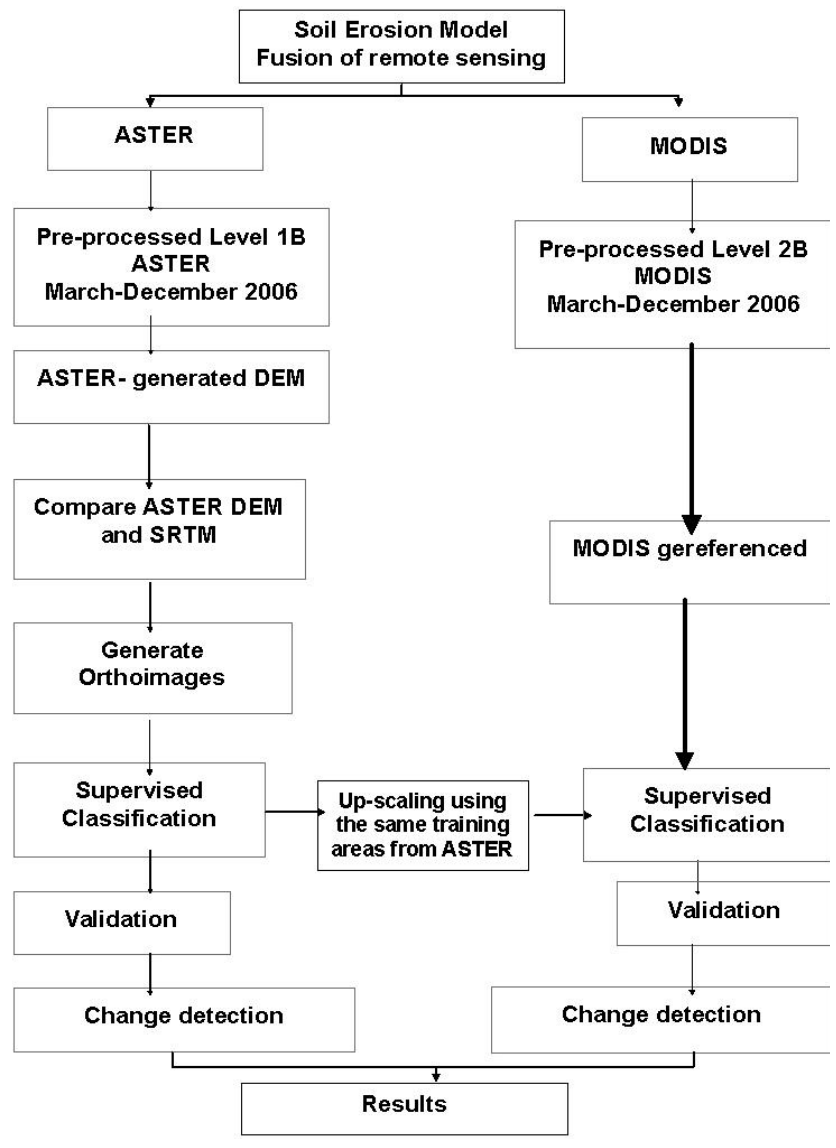

Fig. 3. Flow diagram summarising the methodology. On the left hand side are the steps involved using ASTER and On the right hand side are those involving MODIS. The change in area of eroded land between March and December 2006 is calculated on both MODIS and ASTER scales.

Briefly, the first three (NADIR) channels $123 \mathrm{~N}$ and the back looking channel 3B of ASTER 30 March 2006 are read as two separate .pix files in PCI Geomatica's orthoengine using Toutin's low resolution model. The scenes are reprojected to UTM WGS1984 Zone $36 \mathrm{~N}$ projection. The ground control points (GCPs) necessary for estimating the model parameters are collected from a hillshade image of SRTM generated in ArcGIS 9.3. The reason for using the hillshade of SRTM for collecting GCPs is due to the lack of accurate topographic maps for the study area. The hillshade SRTM ensures better co-registration between the SRTM and ASTERderived products later in the combination process between the two. In total 29 GCPs are collected for each image (Table 2). The Root Mean Square Error (RMSE) for NADIR $123 \mathrm{~N}$ is 0.98 pixels $(\approx 13.3 \mathrm{~m})$ and for the back-looking $3 \mathrm{~B}$ is 1.69 pixels $(\approx 23.8 \mathrm{~m})$. The two images $123 \mathrm{~N}$ and $3 \mathrm{~B}$ are tied together using 95 tie points. The maximum residual for tie points is 0.77 pixels $(\approx 8.67 \mathrm{~m})$. Using cubic transformation and SRTM as the DEM source, a $60 \mathrm{~m}$ resolution DEM (March DEM) is extracted from 30 March ASTER image. 
Table 2. Generation of DEM from two ASTER images. The table summaries the root mean square error (RMSE) for the ground control points (GCPs) for 123N and 3B image channel.

\begin{tabular}{llllll}
\hline Image & Channel & GCP & RMSE & X RMSE & Y RMSE \\
\hline ASTER March & Nadir 123 N & 29 & 0.98 pixels $(13.3 \mathrm{~m})$ & 0.81 pixel $(12.00 \mathrm{~m})$ & 0.65 pixel $(8.01 \mathrm{~m})$ \\
ASTER March & Back-looking 3B & 29 & 1.69 pixels $(23.8 \mathrm{~m})$ & 0.87 pixel $(11.90 \mathrm{~m})$ & 1.31 pixel $(17.3 \mathrm{~m})$ \\
ASTER December & Nadir 123 N & 31 & 1.08 pixels $(14.6 \mathrm{~m})$ & 0.84 pixel $(12.06 \mathrm{~m})$ & 0.67 pixel $(8.29 \mathrm{~m})$ \\
ASTER December & Back-looking 3B & 31 & 1.72 pixels $(24.2 \mathrm{~m})$ & 0.91 pixel $(13.0 \mathrm{~m})$ & 1.47 pixel $(20.4 \mathrm{~m})$ \\
\hline
\end{tabular}

The same procedure is repeated using the second ASTER image of 18 December. The RMS is shown in Table 2. A second $60 \mathrm{~m}$ resolution DEM (December DEM) is also extracted.

\subsection{ASTER classification}

After orthoprojecting ASTER images using SRTM, the channels that best describe the process of soil erosion are selected. Considering the spatial width of gullies, ASTER's VNIR and SWIR channels at $15 \mathrm{~m}$ spatial resolution have been analysed. Additional layers that represent some of the most important natural factors causing erosion are added. These layers are elevation, slope, aspect, and river flow network. Therefore the final ASTER orthoimages used for classification consisted of 13 layers stacked together. These include: VNIR channels 1, 2 and 3, SWIR channels 4, 5, 6, 7, 8 and 9, SRTM, slope, aspect, and river flow network. The last three layers; slope, aspect and river flow network are all calculated from SRTM in ArcGIS 9.3. Both slope and aspect are calculated from SRTM using a finite difference method that uses eight neighbours in ArcGIS. The two are then resampled to $15 \mathrm{~m}$ before adding them to the layer stack. The river flow network was estimated using the hydrologic analysis package in ArcGIS 9.3 as follows. When working with raster DEMs and computing slopes between grid cells, the ratio of the vertical and horizontal resolutions determines the minimum non-zero slope that can be resolved. In this study, the vertical resolution of the DEM is $1 \mathrm{~m}$ and a grid size is $15 \mathrm{~m}$. Therefore the resolvable slope of $1 / 15=0.07$. This value means that slopes on hillsides can be computed with a relatively small error. However, slopes in channels are often much smaller than this value. As a consequence, these areas will appear horizontal in the DEM. Therefore in order to avoid this problem, ArcGIS 9.3 uses an eight direction (D8) flow model. The direction of flow is determined by finding the direction of steepest descent, or maximum drop, from each cell. This is calculated as

maximum drop $=$ change in $\mathrm{z}$-value/distance

The distance is calculated between cell centres. There are eight valid output directions relating to the eight adjacent cells into which flow could travel. One challenge arises if all neighbours are higher than the processing cell. In such a case the processing cell is called a sink and has an undefined flow direction because any water that flows into a sink cannot flow out. To obtain an accurate representation of flow direction across a surface, the sinks should be filled. The minimum elevation value surrounding the sink will identify the height necessary to fill the sink so the water can pass through the cell. A digital elevation model free of sinks is called depressionless DEM. Using the depressionless DEM as an input to the flow direction process, the direction in which water would flow out of each cell is determined. After determining the flow direction, then the flow accumulation is determined. Afterwards, a stream network is created by applying a threshold value to select cells with high accumulated flow in order delineate the stream network. More details on the technique of deriving flow direction from a DEM and on how to create river network in ArcGIS can be found in Jenson and Domingue (1988) and in Tang and Liu (2008), among others.

After stacking all appropriate layers, then supervised maximum likelihood classification is performed aided by the authors' knowledge of the area. The image is trained into four land cover types: Gully, Flat_land, Mountain and Water. Water bodies are clear and easy to train considering the fine ASTER resolution for both periods of the year. Mountains are easily classified with the aid of the DEM. However, the most challenging task is to separate between Gully and Flat_land since these two classes are bound to overlap and overlapping training area boundaries reduces the reliability of the training sites. To avoid this kind of overlap, the following steps were taken

1. MODIS vegetation indices (VI) are used as auxiliary data to discriminate between training classes; Gully and Flat_land. At first MODIS NDVI and EVI signatures are used to discriminate between two classes: stable vegetation and unstable vegetation. The unstable vegetation is seasonal vegetation that grows during the rainy season; this vegetation is flushed away with erosion, indicating that areas where there is unstable vegetation there is also erosion. The stable vegetation on the other hand is there throughout the year hence no erosion. Where NDVI and EVI values are low, this is an indication of limited, unstable vegetation hence higher erosion risk. 
Higher values of NDVI and EVI indicate more stable vegetation.

2. The layer of river network is superimposed on top of the image to help guide and discriminate between Gullies and Flat_land.

3. Care is taken when selecting the different bands both for display, in either greyscale or as false colour composites FCC.

4. Between each run and the next the classes are refined by varying the number of training areas until better accuracies are achieved.

As many training areas as possible are trained because generally speaking, the more areas identified as training sites, the higher the accuracy of the classification. Once the training areas are defined, then the signature separability values are studied. Signature separability is the statistical difference between pairs of spectral signatures. It is expressed in terms of Bhattacharrya Distance and Transformed Divergence. These are measures of the separability of a pair of probability distributions. Both Bhattacharrya Distance and Transformed Divergence are shown as real values between zero and two. Zero indicates complete overlap between the signatures of two classes; two indicates a complete separation between the two classes. The higher the separability (i.e. more than 1.5) value the more accurate is the classification accuracy. The training areas are tuned until higher signature separability value of 1.5 or more are achieved. After achieving the best accuracies, the signature statistics report is studied in order to determine which channels of the 13 stacked layers are more significant in delineating erosion gullies.

\subsection{Post classification}

ASTER classification is validated via running an automatic random accuracy assessment. The accuracy assessment is designed and implemented by generating a random sample of 300 points and comparing it to the original orthorectified ASTER image. ASTER image is used as a reference image due to lack of accurate and updated maps for the study area. Each of the 300 samples is assigned to the different classes.

Once the two ASTER images are successfully classified and validated, they are used to study the bi-temporal change. For each image the area represented by each of the four classes is calculated using the function Generate Area Report in PCI Geomatica. The areas in December image are subsequently subtracted from their correspondent in March image in order to calculate the changed area per class.

\subsection{Upscaling using MODIS}

Once ASTER classification results are accepted, the results are then up-scaled using MODIS. Upscaling allows generalisation of the results of ASTER classification to larger area covering the whole of the Blue Nile region. MODIS is first re-projected to UTM WGS1984 Zone $36 \mathrm{~N}$. Thereafter, it is trained into four classes; Gully, Flat_land, Mountain and Water. MODIS is trained using:

1. MODIS NDVI and EVI are used as auxiliary data to discriminate between training classes; Gully and Flat_land discriminating first between high values i.e. stable vegetation i.e. no erosion and low values i.e. unstable vegetation i.e. erosion areas.

2. The same training areas from ASTER which are converted into shape file and laid over the MODIS image to guide the training.

3. River flow network layer overlaid over the images to guide the training of gullies

MODIS classification is validated against field data in terms of registered digital photos with co-ordinates and time taken in January 2007 from different locations.

\section{Results and discussion}

\subsection{Comparison of the three DEMs}

Because the two generated ASTER DEMs cannot be tested against an existing reference DEM, they are tested through the overlay of different orthoimages taken from different sensor positions (also know as multi-incidence angle image). For 30 March ASTER, two orthoimages are produced one for $123 \mathrm{~N}$ and another for 3B using March DEM. The two orthoimages are then overlaid to test if they overlap perfectly well pixel-by-pixel using animation flickering techniques. The results showed that the two did not overlap perfectly. The explanation for this is that the used March DEM has vertical errors which translated into horizontal shifts between the orthoprojected pixels. These shifts cause the two multi-incidence images not to overlap perfectly. Next December DEM is tested in a similar manner. The results of the flickering technique showed some vertical errors. It is then concluded that the two ASTER DEMs both suffer vertical errors. Accordingly SRTM is selected as "reference DEM" for all further steps. In order to quantify the error of ASTER March and December DEMs, their contour lines are compared to those of SRTM (Fig. 4a and b, respectively). The depicted test area in the figure represents rugged high-mountain conditions with elevations of up to $1500 \mathrm{~m}$ a.s.l., steep rock walls, deep shadows that are without contrast. Therefore, the test area is considered to represent a worst case for DEM generation from ASTER data.

Figure $4 \mathrm{a}$ and $\mathrm{b}$ shows that the contour lines of two ASTER DEMs (dotted lines) are different to those of the SRTM (solid lines) and that this difference increases with elevation. Figure $4 \mathrm{~b}$ shows that December DEM has more 


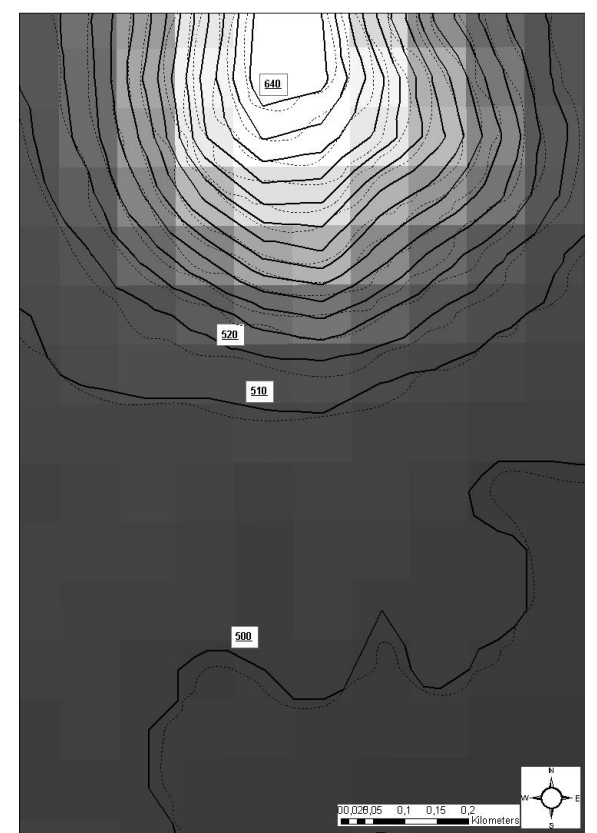

(a)

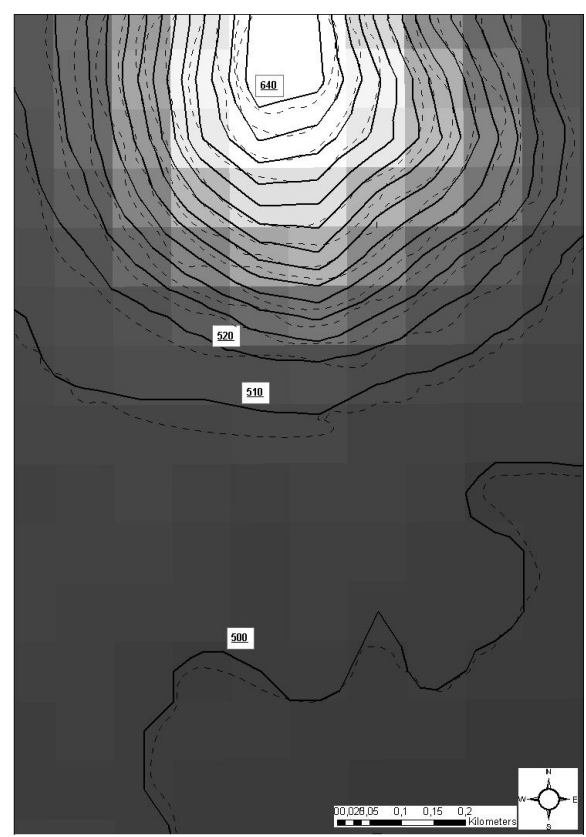

(b)

Fig. 4. Elevation differences between SRTM DEM (solid line) and ASTER (dotted line) (a) ASTER March 2006 and (b) ASTER December 2006; all contour lines are superimposed over a hillshade of the SRTM. The scenes mark a subset with a mix of moderate to high topography representing the worst case scenario of DEM errors.

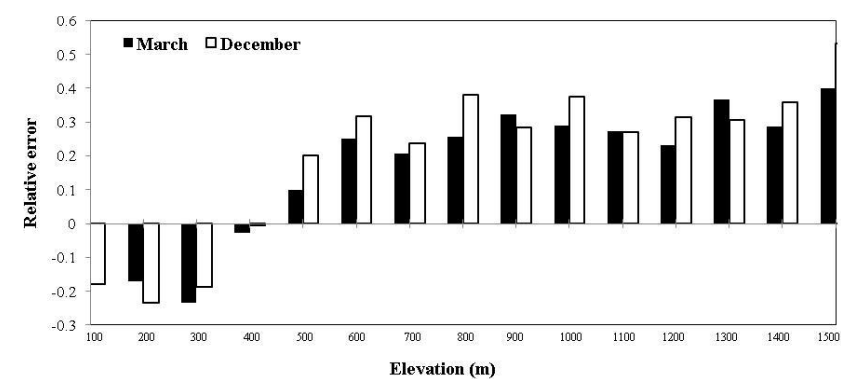

Fig. 5. Comparisons between SRTM and ASTER DEM showing the relative error of the two DEMs March and December from SRTM.

deviation from SRTM than March DEM (Fig. 4a). The relative error of the two ASTER DEMs from the "reference" SRTM is plotted and shown in Fig. 5. Figure 5 shows that up to $400 \mathrm{~m}$ elevation, the two DEMs have lower values than SRTM. They are also similar in magnitude. After $400 \mathrm{~m}$ the two DEMs then have higher values than SRTM at higher altitudes.

The overall conclusions of the DEM comparisons are:

- Using orthoimage overlay techniques for multiincidence angle images, it is found clearly that the two ASTER-generated DEMs suffer vertical errors and are less accurate because of the low optical and radiometric image contrast resulting from the fact that the study area is predominantly rural with few land cover/use classes. Also the accuracy of GCPs is among the main factors limiting the accuracy of ASTER DEM.

- Compared to the SRTM, ASTER DEM systematically overestimates elevation at higher latitudes while it underestimates elevation at low altitudes. These maximum errors occur at sharp ridges or deep gullies.

- Compared to SRTM December DEM is more accurate up to $400 \mathrm{~m}$ elevation, after that it has errors of larger magnitude than March DEM

Accordingly SRTM was used to orthoproject the two ASTER images for classification purposes.

\subsection{Factors affecting gully erosion}

In order to understand which input channels mostly contributed to gully identification the standard deviation of the signatures for each of the 13 channels for ASTER March and December are plotted in Fig. 6a and b, respectively. Figure 6a and $b$ gives an overview of the contribution of the different channels in the identification of the class Gully. Channels that have high standard deviation values are the least significant in delineating gullies and vice versa. In March which is the dry season (Fig. 6a), river network and slope have the highest standard deviation. In December, however (Fig. 6b), 


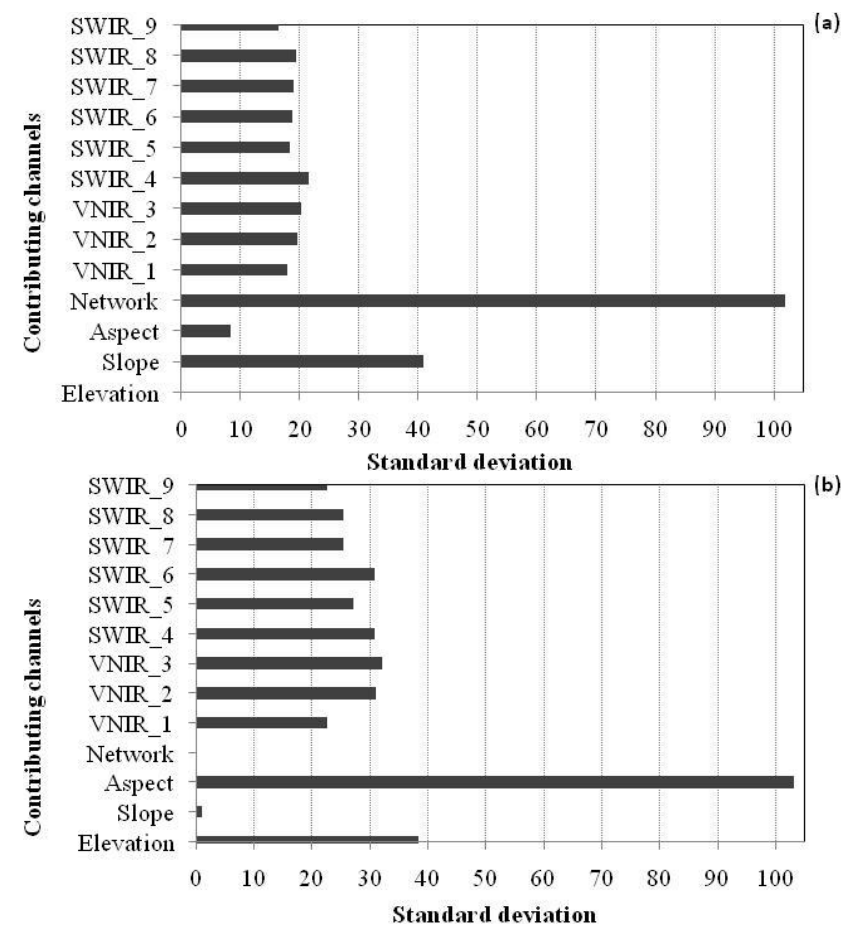

Fig. 6. The contribution of the different input channels in delineating gullies in ASTER images (a) March, (b) December.

Table 3. Classification report of ASTER images.

\begin{tabular}{lccc}
\hline Image & $\begin{array}{c}\text { Average } \\
\text { accuracy }\end{array}$ & $\begin{array}{c}\text { Overall } \\
\text { accuracy }\end{array}$ & $\begin{array}{c}\text { Kappa } \\
\text { coefficient }\end{array}$ \\
\hline ASTER March & $93.4 \%$ & $82.2 \%$ & 0.82 \\
ASTER December & $87 \%$ & $75.2 \%$ & 0.75 \\
\hline
\end{tabular}

they have the lowest standard deviation values and hence they are the most important in Gully classification. During and after the rainy season, river network and slope are the most important factors in the erosion process. In December river networks continue to flow even when the rain has stopped carrying with the flow soil and weathered rock debris from hill slopes and valley walls and as slope steepness increase, the amount of water contributed by upslope areas and the velocity of water flow increase, hence stream power and potential erosion increase. As natural factors, river flow network and slope are more important in causing erosion in the Blue Nile region than aspect and elevation.

\subsection{Validation of the classification outcome}

ASTER classification reports (Table 3) shows an overall accuracy of $82.2 \%$ and $75.2 \%$ for March and December images, respectively. And similarly for ASTER validation, the

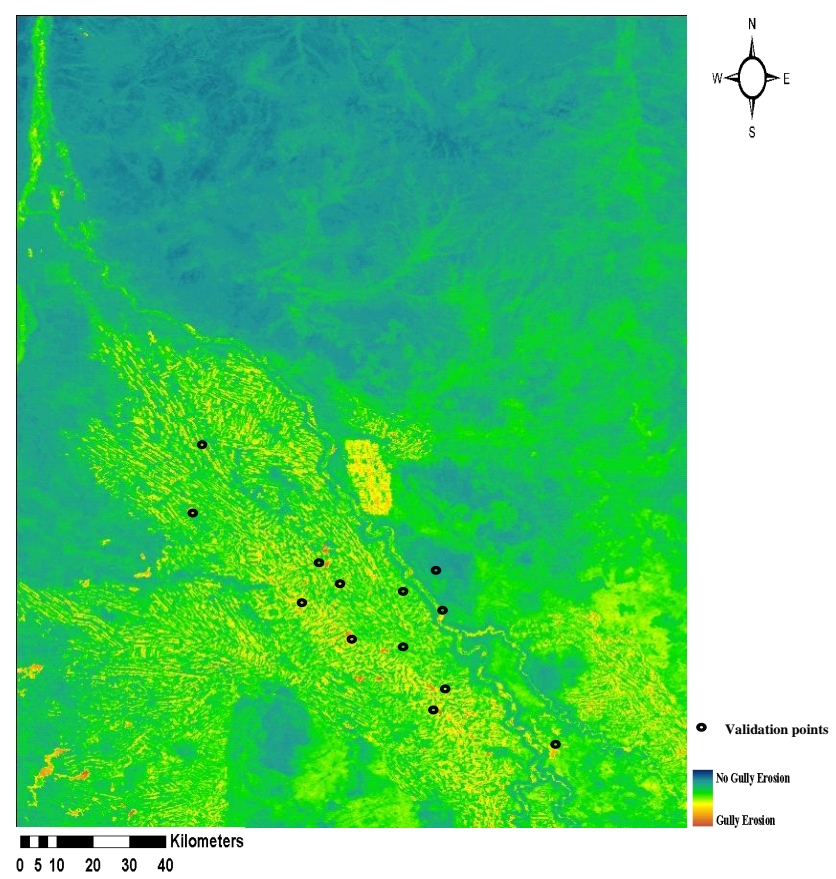

Fig. 7. Regional spatial distribution map of seasonal gullies of the Blue Nile, Eastern Sudan.

accuracy assessment report (Table 4) shows that in March the overall accuracy is $93 \%$ and in December is $89 \%$. The classification of March image is better than December because VNIR and SWIR channels are more capable of discriminating erosion gullies in the dry season due to higher spectral reflectance.

MODIS classification accuracies for March and December are $77.2 \%$ and $81.0 \%$ respectively (Table 5). Automatic accuracy assessment (Table 6) shows overall accuracies of $89 \%$ and $88.7 \%$ for March and December, respectively. Additionally, the classified MODIS image is validated against a set of thirteen digital photos taken in the field. Nine validation points showed gullies coinciding with the results of the classification (Fig. 7). In March classification is better than that of December because in the dry season there is less soil moisture therefore higher surface reflectance. The overall accuracy of MODIS is less than that of ASTER. The reasons are that there is insufficient spectral distinctiveness due to the low spectral and spatial resolution of the MODIS data; MODIS products consisted of averaged products rather than the actual spectral bands; some artefacts interfered with the calculation of eroded areas.

\subsection{Estimation of soil erosion on ASTER scale}

The results of the bi-temporal change of gully erosion in ASTER scale are shown in Table 7. Table 7 shows an increase by approximately $112 \mathrm{~km}^{2}$ in the area of gullies. This is because after the rainy season, both rain and flood water 
Table 4. Validation of ASTER classification: accuracy statistics report indicating the outcome of the accuracy assessment of the used supervised maximum likelihood classifier.

\begin{tabular}{|c|c|c|c|c|}
\hline & Class name & Producer's accuracy & User's accuracy & Kappa statistic \\
\hline \multirow{6}{*}{ ASTER March } & Mountain & $88.2 \%$ & $97.8 \%$ & 0.97 \\
\hline & Gully & $92.2 \%$ & $92.2 \%$ & 0.90 \\
\hline & Flat & $96.3 \%$ & $92.3 \%$ & 0.83 \\
\hline & Water & $70.0 \%$ & $87.5 \%$ & 0.87 \\
\hline & \multicolumn{2}{|c|}{ Overall accuracy } & \multicolumn{2}{|c|}{$93.0 \%$} \\
\hline & Class Name & Producer's accuracy & User's accuracy & Kappa statistic \\
\hline \multirow{5}{*}{ ASTER December } & Mountain & $69.2 \%$ & $75.0 \%$ & 0.74 \\
\hline & Gully & $87.0 \%$ & $85.3 \%$ & 0.78 \\
\hline & Flat & $95.2 \%$ & $79.7 \%$ & 0.75 \\
\hline & Water & $91.7 \%$ & $100 \%$ & 1.00 \\
\hline & \multicolumn{2}{|c|}{ Overall accuracy } & \multicolumn{2}{|c|}{$89.0 \%$} \\
\hline
\end{tabular}

Table 5. Classification report of MODIS products.

\begin{tabular}{lccc}
\hline Image & $\begin{array}{c}\text { Average } \\
\text { accuracy }\end{array}$ & $\begin{array}{c}\text { Overall } \\
\text { accuracy }\end{array}$ & $\begin{array}{c}\text { Kappa } \\
\text { coefficient }\end{array}$ \\
\hline MODIS March & $77.2 \%$ & $61.9 \%$ & 0.40 \\
MODIS December & $81.0 \%$ & $63.8 \%$ & 0.20 \\
\hline
\end{tabular}

dissects large areas creating either new gullies or increasing the width and/or depth of existing gullies. Naturally an increase in dissected land reduces the extent of flat land. That is why there is a decrease of flat land by about $153 \mathrm{~km}^{2}$. The area covered with water has increased by $31.5 \mathrm{~km}^{2}$. That is due to the fact that in December there are still large areas that are covered with rain and flood water from the rainy season time which have not receded, percolated or evaporated yet. The total area classified as mountains did not change. In fact this is regarded as an indication of the success of the classification because when stable features like mountains remain stable then this is regarded as an indication of good georeferencing and subsequently good multitemporal analysis (Kääb, 2005).

\subsection{Estimation of erosion on a regional scale}

The change in the total area of gullies is estimated by subtracting the area in MODIS December image from that in MODIS March (Table 8). Table 8 shows that gullies have increased by approximately $2071 \mathrm{~km}^{2}$, and water by $1791 \mathrm{~km}^{2}$, respectively. Flat_land has decreased by $3864 \mathrm{~km}^{2}$ while mountains remained unchanged. Hence the estimated area along the Blue Nile River, Eastern Sudan that was affected by soil erosion during the 2006 rainy season was estimated to be $2071 \mathrm{~km}^{2}$ or $6.5 \%$ of the total study area approximately. This estimation should be viewed in light of the facts that: (a) the year 2006 was exceptionally wet year compared to previous years, (b) the Upper Blue Nile River is steeper and receives more rain than any other river in Sudan namely, the White Nile, River Atbara, Sobat, etc., and (c) there has not been any previous studies reported in this region.

After close comparison and evaluation of the soil erosion model as presented above, it is used to map the spatial distribution of gully erosion in the Blue Nile region during 2006 seasonal rains (Fig. 7). It is seen in the figure that gully erosion is evident in and around the Blue Nile River and its tributaries.

\section{Summary and conclusion}

Soil erosion poses a serious environmental and socioeconomic threat to the environment and to mankind. Previous research in sub-Sahara Africa has singled out the Upper Blue Nile as an erosion prone area that is recommended for further monitoring and evaluation. In this study a soil erosion area model is suggested. The model benefits from advances in GIS and remote sensing fusion techniques. The model is simple, robust and straightforward. It makes use of the well tested methods of supervised classification using maximum likelihood (MLC). Generalisation of ASTER classification results using MODIS was useful for capturing a regional impression of the spatial distribution of erosion. Key to the model's success is further development of proper validation procedures. The size of this region makes the traditional mapping methods of aerial photography and field surveying of limited use. Moderate resolution multispectral data allows continental- to global-scale mapping of the Earth's surface 
Table 6. Validation of MODIS classification: accuracy statistics report indicating the outcome of the accuracy assessment of the used supervised classifier.

\begin{tabular}{|c|c|c|c|c|}
\hline & Class name & Producer's accuracy & User's accuracy & Kappa statistic \\
\hline \multirow{6}{*}{ MODIS March } & Mountain & $94.1 \%$ & $80.0 \%$ & 0.76 \\
\hline & Gully & $90.6 \%$ & $93.6 \%$ & 0.91 \\
\hline & Flat & $89.7 \%$ & $89.7 \%$ & 0.83 \\
\hline & Water & $75.0 \%$ & $90.0 \%$ & 0.89 \\
\hline & \multicolumn{2}{|c|}{ Overall accuracy } & \multicolumn{2}{|c|}{$89.0 \%$} \\
\hline & Class name & Producer's accuracy & User's accuracy & Kappa statistic \\
\hline \multirow{5}{*}{ MODIS December } & Mountain & $91.2 \%$ & $80.0 \%$ & 0.74 \\
\hline & Gully & $87.6 \%$ & $92.5 \%$ & 0.88 \\
\hline & Flat & $85.7 \%$ & $89.9 \%$ & 0.70 \\
\hline & Water & $72.6 \%$ & $91.4 \%$ & 0.89 \\
\hline & \multicolumn{2}{|c|}{ Overall accuracy } & \multicolumn{2}{|c|}{$88.7 \%$} \\
\hline
\end{tabular}

Table 7. Local change of erosion area as indicated by the difference (diff) in area percentage $(\%)$ or in $\mathrm{km}^{2}$ between March and December 2006 for the four land cover classes.

\begin{tabular}{lrrrrrr}
\hline \multirow{2}{*}{ Class } & \multicolumn{3}{c}{ Area (\%) } & \multicolumn{3}{c}{ Area $\left(\mathrm{km}^{2}\right)$} \\
& Mar & Dec & Diff & Mar & Dec & Diff \\
\hline Gully & 42.1 & 50.9 & 8.77 & 538.5 & 650.7 & 112.2 \\
Flat land & 46.6 & 34.63 & -12 & 596 & 442.9 & -153.1 \\
Mountain & 4.43 & 4.43 & 0.00 & 56.7 & 56.701 & 0.05 \\
Water & 6.87 & 10.07 & 3.20 & 67.9 & 99.49 & 31.59 \\
\hline
\end{tabular}

Table 8. Regional change of erosion area as indicated the difference (diff) in area percentage $(\%)$ or in $\mathrm{km}^{2}$ between March and December 2006 for the four land cover classes.

\begin{tabular}{lccrrrr}
\hline \multirow{2}{*}{ Class } & \multicolumn{3}{c}{ Area $(\%)$} & \multicolumn{3}{c}{ Area $\left(\mathrm{km}^{2}\right)$} \\
& Mar & Dec & Diff & Mar & Dec & Diff \\
\hline Gully & 33.1 & 39.7 & 6.55 & 10467 & 12538 & 2071 \\
Flat land & 39.8 & 27.6 & -12.2 & 12572 & 8708 & -3864 \\
Mountain & 21.3 & 21.3 & 0 & 6737 & 6737 & 0 \\
Water & 5.84 & 11.5 & 5.67 & 1845 & 3636 & 1791 \\
\hline
\end{tabular}

while retaining sufficient resolution for geomorphic and ecological studies.

The following conclusions are drawn from the study:

1. ASTER-derived DEMs are less accurate than SRTM because of the low optical contrast of the study area which is predominantly rural with few land cover/use classes low.
2. The incision of gullies found in this area is strongly associated with topography, especially river flow networks and slope.

3. Moreover, on-going climate change can initiate new processes via increased rainfalls, or weaken land cover.

The model can be used to study longer-term changes in erosion by using time series of images from different years. The methodology presented here is also transportable to other arid and semi-arid parts of Sudan where an understanding of soil erosion is desirable.

Acknowledgements. Our appreciation extends to the Norwegian Research Council (NFR) for sponsoring the project number 171783 (FRIMUF), Department of Geosciences, University of Oslo, Faculty of Engineering, University of Khartoum, The Forestry, Irrigation and Environment National Corporations of Sudan.

Edited by: N. Romano

\section{References}

Abdulkarim, A.: Rainfall variability in the Blue Nile state, in: Reports of the National Meteorological Office, Khartoum, Sudan, 2006.

Ahmed, A., Osman, I., and Babiker, A.: Sediment and Aquatic Weeds Management Challenges in Gezira Irrigated Scheme in: Proceedings, UNESCO's International Sediment Initiative Conference (ISIC), Khartoum, Sudan, 12-15 November 2006.

Ayoub, A. T.: Extent, Severity and Causative Factors of Land Degradation in Sudan, J. Arid Environ., 38, 397-409, 1998.

Bull, W. B.: Soils, geology, and hydrology of deserts, in: Water in desert ecosystems, edited by: Evans, D. D. and Thames, J. L., Stroudsberg, Pa, Dowden, Hutchinson and Ross, USA, 42-58, 1981.

Dan, J. and Koyumdjisky, H.: Distribution of salinity in the soils of Israel, Israel J. Earth Sci., 36, 213-223, 1987. 
Dan, J. and Yaalon, D. H.: Automorphic saline soils in Israel, in: Aridic soils and geomorphic processes, edited by: Yaalon, D. H., Cathena Verlag, 1, Braunschweig, Germany, 103-115, 1982.

Dan, J., Moshe, R., and Alperovitch, N.: The soils of Sede Zin, Israel J. Earth Sci., 22, 211-227, 1973.

Gao, X., Huete, A., Ni, W., and Miura, T.: Optical -biophysical relationships of vegetation spectra without background contamination, Remote Sens. Environ., 74, 609-620, 2000.

Gomer, D. and Vogt, T.: Physically based modelling of surface runoff and soil erosion under semi-arid Mediterranean conditions, the example of Oued Mina, Algeria, in: Soil Erosion: Application of Physically based models, edited by: Schmidt, J., Springer Verlag, Berlin, Heidelberg, New York, 58-78, 2000.

Jenson, S. K. and Domingue, J. O.: Extracting Topographic Structure from Digital Elevation Data for Geographic Information System Analysis, Photogrammetric Engineering and Remote Sensing, 54(11), 1593-1600, 1988.

Kääb, A., Huggel, C., Fischer, L., Guex, S., Paul, F., Roer, I., Salzmann, N., Schlaefli, S., Schmutz, K., Schneider, D., Strozzi, T., and Weidmann, Y.: Remote sensing of glacier- and permafrostrelated hazards in high mountains: an overview, Nat. Hazards Earth Syst. Sci., 5, 527-554, doi:10.5194/nhess-5-527-2005, 2005.

Kääb, A.: Combination of SRTM3 and repeat ASTER data for deriving alpine glacier flow velocities in the Bhutan Himalaya, Rem. Sens. Environ., 94(4), 463-474, 2005.

Linsely, R. K., Kohler, M. A., and Paulhus, J. L. H.: Hydrology for Engineers, Third Edition, International Student Edition, McGraw-Hill Kogakusha, Ltd, New Delhi, India, 1982.

Mirghani, O.: Report on the Field Visit to Sennar and Blue Nile States, in: Field work report, 2007.

Mokwunye, U.: Nutrient depletion: sub-Saharan Africa's greatest threat to economic development, S.T.A.P. expert workshop on Land Degradation Dakar, Senegal, 1996.

Moore, I. D., O'Loughlin, E. M., and Burch, G. J.: A contourbased topographic model for hydrological and ecological applications, Earth Surf. Processes Landforms, 3(4), 305-320, 1988.

Nakileza, B., Nsubuga, E., Tenywa, M., and Lwakuba, A.: Rethinking Natural Resource Degradation in Semi-Arid Sub-Saharan Africa: A review of soil and water conservation research and practice in Uganda, with particular emphasis on the semi- arid areas, Overseas Development Institute (ODI) Report, 1999.

Nearing, M. A., Pruski, F. F., and O'Neal, M. R.: Expected climate change impacts on soil erosion rates, a review, J. Soil Water Conservation, 59(1), 43-50, 2004.

Nir, D. and Klein, M.: Gully erosion induced in land size in a semiarid terrain (Nahal Shiqma, Israel), Zeitschrift fur Geomorphologie, 21, 191-201, 1974.

Ritter, F., Kochel, R., and Miller, J.: Process Geomorphology, 4th Ed., McGraw-Hill, New York, 2002.
Rozin, U. and Schick, A.: Land use change, conservation measures and stream channel response in the Mediterranean/semiarid transition zone: Nahal Hoga, southern coastal plain, Israel, in: Erosion and sediment yield global and regional perspectives, IAHS publ., 236, 427-443, 1996.

Schlesinger, W., Reynolds, J. F., Cunningham, G. L., Huenneke, L. F., Jarrell, W. M., Virginia, R. A., and Whitford, W. G.: Biological feedbacks in global desertification, Science, 247, 1043-1048, 1990.

Shalhevet, J. and Bernstein, L.: Effects of vertically heterogeneous soil salinity on plant growth and water uptake, Soil Science, 106, 85-93, 1968.

Symeonakis, E. and Drake, N.: Monitoring Desertification and Land Degradation over Sub- Saharan Africa, Int. J. Rem. Sens., 25(3), 573-592, 2004.

Tang, C. and Liu, C.: Surface water hydrologic simulation of Qingshuijiang Watershed based on SRTM DEM, Proc. The International Society for Optical Engineering SPIE, 7143, doi:10.1117/12.812556, 2008.

Thornes, J. B.: The interaction of erosional and vegetation dynamics in land degradation: spatial outcomes, in: Vegetation and Erosion, edited by: Thornes, J. B., Chichester, John Wiley, 41-53, 1990.

Toutin, T. and Cheng, P.: Comparison of automated digital elevation model extraction results using along-track ASTER and acrosstrack SPOT stereo images, Optical Engineering, 41(9), 21022106, 2002.

Toutin, T. and Cheng, P.: DEM generation with ASTER stereo data, Earth Observation Magazine, 10(6), 10-13, 2001.

Toutin, T.: DEM generation from new VIR Sensors, IKONOS, ASTER and Landsat 7 Proceedings, IGARSS 01, Sydney, Australia 2001.

Toutin, T.: Three-dimensional topographic mapping with ASTER stereo data in rugged topography, IEEE Trans. Geosci. Rem. Sens., 40, 10, 2241-2247, 2002.

Vrieling, A., Jong, S., Sterk, G., and Rodrigues, S.: Timing of erosion and satellite data: A multi-resolution approach to soil erosion risk mapping, Int. J. Appl. Earth Obs., 10, 267-281, 2008.

Ward, D. and Olsvig-Whittaker, L.: Plant species diversity at the junction of two desert biogeographic zones, Biodiversity Lett., 1, 172-185, 1993.

Ward, D., Feldman, K., and Avni, Y.: The effects of erosion loess on soil nutrients, plant diversity and plant quality in Negev desert wadis, J. Arid Environ., 48, 461-473, 2001.

West, N. E.: Nutrient cycling in soils of semiarid and arid regions, in: Semiarid Lands and Deserts: Soil Resource and Rehabilitation, edited by: Skujins, J., Marcel Dekker, Inc., New York, 295-332, 1991.

Xu, C-Y., Zhang, Q., El Hag El Tahir, M., and Zhang, Z.: Statistical properties of the temperature, relative humidity, and solar radiation in the Blue Nile- Eastern Sudan region, J. Theoret. Appl. Climatol., doi:10.1007/00704009-0225-7, 2009. 